\title{
Environmental indoor thermal control of extra virgin olive oil storage room with phase change materials
}

\author{
Francesco Barreca, Pasquale Praticò \\ Department of Agriculture, University of Reggio Calabria, Italy
}

\begin{abstract}
The quality of extra virgin olive oil (EVOO) is strongly correlated to storage temperature, in fact the storage conditions (packaging material, oxygen, temperature, and light) alters not only the fatty acid alkyl esters (FAEE) of the olive oil but also other quality parameters such as peroxide, making the oil incompatible to the high quality EVOO. During storage of EVOO the polyphenols tend to decrease and compromise the dietetic and nutritional qualities and taste and produce harmful substances. The storage temperature, more than $24^{\circ} \mathrm{C}$, influences quite a lot FAEE especially for long-term conservation. High storage temperature leads to degradation of oil quality in the long term while low temperature develops rancidity quickly, reducing the consumer's demand. Low storage temperature also affects the EVOO quality but in a lesser way than high storage temperature. The present study proposes the use of a control temperature system based on the application of phase change materials (PCM) on the buildings envelope. A specific case study was considered to evaluate the effect on use of PCM. The building analysed was an olive mill building situated in Scido a small town in the province of Reggio Calabria located in southern Italy. The intervention on the EVOO storage room to improve the energy savings for temperature control was based on the insulation of the partitions and the installation of a false ceiling to limit the air volume, with a two layer panel sandwich, one of
\end{abstract}

Correspondence: Francesco Barreca, Department of Agriculture, University of Reggio Calabria, località Feo di Vito, 89123 Reggio Calabria, Italy.

Tel.: +39.096516942. E-mail: fbarreca@unirc.it

Key words: Energy analysis; extra virgin olive oil; food building; phase change materials; polyphenols.

Acknowledgements: the research was funded by the project Proof of Concept, POC01_00052 included in the Programma Nazionale della Ricerca 2015/2020 of MIUR.

Received for publication: 14 February 2019.

Accepted for publication: 27 May 2019.

(C) Copyright: the Author(s), 2019

Licensee PAGEPress, Italy

Journal of Agricultural Engineering 2019; L:947

doi:10.4081/jae.2019.947

This article is distributed under the terms of the Creative Commons Attribution Noncommercial License (by-nc 4.0) which permits any noncommercial use, distribution, and reproduction in any medium, provided the original author(s) and source are credited.
PCM and the other of a rigid polyurethane foam with a $4 \mathrm{~cm}$ thick metal cladding. A thermal analysis simulation, by means of DesignBuilder software, was conducted. To calculate the electric energy spent in a year to control air temperature in a range of 8$22^{\circ} \mathrm{C}$. The results were of $3590.67 \mathrm{kWh} /$ year for existing building and $2539.52 \mathrm{kWh} /$ year for building with PCM, energy save of about $30 \%$. A temperature decrease of about $3{ }^{\circ} \mathrm{C}$ was measured inside the storage room without a cooling system during the hottest year period but the most important result was a thermal indoor air stabilisation in the storage room. This condition avoids a thermal fluctuation to the EVOO and it is the best storage condition.

\section{Introduction}

Conservation of food production is an important phase because the most important chemical, physical and biological changes take place during this phase (Barbaresi et al., 2014, 2015), such as some quality parameters of extra virgin olive oil (acidity, peroxide value and UV absorbance) that could vary depending on the time and storage method, leading to undesirable olive oil.

The quality of extra virgin olive oil (EVOO) is strongly correlated to the fatty acid alkyl esters (FAEE) content. In fact researches, which have been carried out, have emphasised the relationship between FAEE in olive oil and its sensory classification and also the defects due to olive fermentation. The FAEE determines the organoleptic profile of an EVOO which plays a relevant role in olive oil classification and it is included among the quality parameters (Gómez-Coca et al., 2016). Nevertheless it has been demonstrated how the content of the FAAE at a high concentration, highlights the fact that olive fruits with fermentative alterations and high maturity index had been used for oil extraction. The storage temperature, more than $24^{\circ} \mathrm{C}$, influences quite a lot FAEE especially for long-term conservation. An incorrect storage temperature interval alters not only the FAEE of the olive oil but also other quality parameters such as peroxide, making the oil incompatible to the high quality EVOO.

The European Commission Regulation of 2016 established that the legal value limit of FAEE content for EVOO is $30 \mathrm{mg} / \mathrm{kg}$.

The concentrated FAEE are not static and under wrong storage conditions they could go over the maximum limit allowed to classify oil as extra virgin, therefore not ranking the highest category. During storage of EVOO the polyphenols tend to decrease and compromise the dietetic and nutritional qualities (Ayton et al., 2012) and taste and produce harmful substances (Lo Curto et al., 2001). Low storage temperature also affects the EVOO quality but in a lesser way than high storage temperature. Researchers noticed that storage temperature below $4^{\circ} \mathrm{C}$ lasting 15 days causes a decrease of about $50 \%$ of the total polyphenols in respect to fresh- 
ly made EVOO (Piscopo and Poiana, 2012). Storage temperature significantly affects the sensory profile of olive oils. High storage temperature leads to degradation of positive oil attributes in the long term, while low temperature develops rancidity quickly and reducing the consumer's acceptance and therefore the shelf life of EVOO (Ayton et al., 2012).

The best EVOO storage range temperature is very difficult to define, because a lot of parameters influence the optimal temperature interval. Olive cultivar, maturity index of the olive fruits, storage tank type, ambient lighting and time of storage, are only some parameters could affect the best storage temperature. For example the best range of temperature for a typical Calabrian EVOO, made with monovarietal Carolea olives, stored in stainless steel tanks and held in a dark environment with an average storage time of 12 months, is between $8^{\circ} \mathrm{C}$ and $22^{\circ} \mathrm{C}$ (Piscopo and Poiana, 2012).

Usually, the conservation stage consumes more energy than other stages, because the energy spent for product units is related to the time of conservation, which is long, and often more than one year. For these reasons thermal control of the storage EVOO environment is very important and the use of passive solutions could improve energy savings of the production.

Spain $\left(1271 \cdot 10^{3} \mathrm{t}\right)$ and Italy $\left(429 \cdot 10^{3} \mathrm{t}\right)$ are the main producers of olive oil in Europe and Italy is the major consumer of olive oil $\left(560 \cdot 10^{3}\right.$ t) (Zolichová, 2017).

Apulia in Italy is the first production region, with $33 \%$ of an olive grove surface area, followed by Calabria, with $17 \%(184,000$ ha), of which about 1550 ha are table olive groves and about 183 ha are oil olive groves, producing 140,000 tons of olive oil annually (Stillitano et al., 2017). In Calabria olive trees are the most cultivated and the most important chain supply, which contribute to local rural economy (Valenti et al., 2017). The greatest surface areas are the provinces of Cosenza and Reggio Calabria (Luca et al., 2018). In particular in the province of Reggio Calabria there is the highest number of olive mills (304) and the highest quantity of olive oil production (26,555 t) (ISMEA, 2018).

The climate in Reggio Calabria is typically Mediterranean, with a mild temperature in winter $\left(\mathrm{T}>0^{\circ} \mathrm{C}\right)$ and warm summers $(\mathrm{T}$ $\max >30^{\circ} \mathrm{C}$ ), with a strong daytime and night-time change of temperature. The environmental indoor temperature of the EVOO mill storage area in summer is often higher than $35^{\circ} \mathrm{C}$ (Barreca and Praticò, 2018).

The present study proposes the use of a control temperature system based on the application of phase change materials (PCM) on the buildings envelope of an olive mill located in a small town of Reggio Calabria province. This solution avoids a thermal fluctuation to the EVOO and it is the best storage condition, in fact the quality of EVOO depends strongly on the storage temperature.

\section{Materials and methods}

A good design of the envelope of a building generally gives an efficient thermal control. In fact the right thermal design of a building should consider the value of a thermal insulation and the thermal capacity of the external partitions (Barreca and Fichera, 2013). The thermal insulation of the walls is very important in cold temperatures whereas the thermal mass of the walls is important in warm temperatures because the material will accumulate excess of heat during the day and will return it in the air when temperature drops during the night. The heat accumulated depends on the mass and on the specific heat of the materials of the wall. Old buildings were build heavy walls endowed with high thermal mass, the mod- ern buildings' walls are lighter with more empty spaces to increase the thermal insulation but this solution decrease the thermal inertia.

The PCM is a heat storage that absorbs the incoming heat flux and removes it from the environment through a melting process, when the temperature decreases, the PCM solidifies and returns the heat to the environment (Caprara and Stoppiello, 2012). The advantage of using the PCM in the building envelope allows: i) to limit the indoor environment heat input and to store it until the indoor temperature decreases; ii) to maintain a constant indoor air temperature during the melting process.

The PCM has two stages called load and unload, in theory these stages could carry on until infinity, but in fact the PCM has a limited number of stages.

The PCM could improve the thermal walls performance because it exchanges heat with the external environment, it absorbs heat when it melts and when it solidifies it releases heat to the environment.

The change phase of the material is with constant temperature and this characteristic is important for insulation material because it allows stabilisation of the environmental indoor temperature. Moreover the heat accumulated (Eq. 1) is due to the exchange of sensible heat when the material is itself in a solid or liquid state:

$$
Q=m \int_{T_{i}}^{T_{m}} c_{p_{s}} d T+m \Delta H_{m}+\mathrm{m} \int_{T_{m}}^{T_{f}} c p_{l} d T
$$

where,

$Q$ is the heat accumulated ( $\mathrm{J})$;

$m$ is the mass of the material, which changes its phase $(\mathrm{g})$;

$\Delta H_{m}$ is the phase change enthalpy variation of the material $\left(\mathrm{J} \cdot \mathrm{g}^{-1}\right)$; $T_{i}-T_{m}$ is the range of temperature of solid material $\left({ }^{\circ} \mathrm{C}\right)$; $T_{m}-T_{f}$ is the range of temperature of liquid material $\left({ }^{\circ} \mathrm{C}\right)$; $c_{p s}$ is the specific heat of the solid material $\left(\mathrm{J} \cdot \mathrm{g}^{-1}{ }^{\circ} \mathrm{C}^{-1}\right)$; $c_{p l}$ is the specific heat of the liquid material $\left(\mathrm{J}^{\circ} \mathrm{g}^{-1}{ }^{\circ} \mathrm{C}^{-1}\right)$.

The design process is quite complex because it has to be carried out by a dynamic thermal model, which has to take into consideration the external heat flux and the behaviour of the PCM at different temperatures. Another essential point is to know the correct latent heat curve. In fact the latent heat curve is often not well defined for all PCMs, because a complex procedure needs a differential scanning calorimeter (Osterman et al., 2012).

The base material of the PCM could be organic (hydrated salts) o inorganic (paraffin), research has recently been looking for more new natural substances for the safety of the environment and for occupants of buildings. It is very important to obtain the right environmental temperature by carrying out a correct design of the PCM system, choosing the right type of material and the best melting temperature but at the same time building the PCM system in the right way. If PCM is used as insulation material of external walls and its temperature is around melting temperature, its behaviour is like that of a total insulation material because the temperature of its mass remains constant until the received thermal energy melts the mass totally (Buonomano et al., 2016). PCM stores not only the latent heat but also a part of sensible heat which changes the temperature of the PCM (Castell et al., 2009).

Figure 1 illustrates the energy stored by the PCM. Sensible heat is absorbed in the solid material with temperature that rises from $20^{\circ} \mathrm{C}$ to $27^{\circ} \mathrm{C}$ (slope of the line is correlated to specific heat of the material), at $27^{\circ} \mathrm{C}$ the temperature starts the melting process and the heat absorbed is totally used to melt the material (the temperature in the material remains constant), when the melting process is completed the heat rises the temperature of the liquid out- 
come (sensible heat). At the end of the process the energy stored in PCM is the sum of both sensible and latent heat. When external heat flux ends (for example at night) the PCM releases the heat stored before and its temperature decreases until solidification starts therefore bringing the PCM to its initial conditions.

\section{The extra virgin olive oil storage room}

The building analysed was an olive mill building situated in Scido a small town in the province of Reggio Calabria in southern Italy ( $38^{\circ} 15^{\prime} 36.1$ " N; $15^{\circ} 56$ ' 28.6 " E). The buildings has $14 \times 35$ $\mathrm{m}$ rectangular plan (Figure 2), the oil storage room has a surface of $130 \mathrm{~m}^{2}$ and the working area has a surface of $450 \mathrm{~m}^{2}$, the vertical building structures are with reinforced concrete and the roof structures are of steel. The external walls are in hollow brick, the covered of the pitched roof is with insulated metal panels, the internal eave height is $7 \mathrm{~m}$. The windows of the building are located on each of the two longer sides of the main unit, but they are not located in the storage olive oil area. The internal environment is naturally ventilated and has neither air-conditioning nor ventilation systems. In particular the olive oil storage room has a dimensions of $7.70 \times 17.00 \mathrm{~m}$ and it is located north of the building. In the storage olive oil area, there are twelve stainless steel tanks, 6 of $4 \mathrm{~m}^{3}$ and 6 of $5 \mathrm{~m}^{3}$, the oil is produced by means of a three-phase system for olive oil extraction from olives cultivar of Carolea and Sinopolese.

\section{Energy software}

The numerical analysis of the PCM needs advanced software of thermal dynamic analysis, which considers the behaviour of the heat capacity of the envelope exposed at a variable external thermal load. In this case study a DesignBuilder version 5.4 software was used and the thermal analysis was carried out considering the closest World Meteorological Organisation (WMO) weather station $\mathrm{n} .164200$ located about $35 \mathrm{~km}$ West from the olive mill under study ( $38^{\circ} 12^{\prime} \mathrm{N} ; 15^{\circ} 33^{\prime} \mathrm{E}$ ) (Figure 3 ). The core of this software is EnergyPlus ${ }^{\mathrm{TM}} 8.6$, which is a simulation Software for numerical analysis. EnergyPlus ${ }^{\mathrm{TM}} 8.6$ is a popular program in literature released by the U.S. Department of Energy. The software allows the building division into thermal zones; each zone is defined as a portion of space composed by an air volume at uniform temperature and by its boundary surface the thermal model is built by the pre-processor of DesignBuilder. It is important for this aim, to define the thermal characteristics of the building component materials, in fact the precision of results depend strongly on the accuracy of the material parameter values such as conductivity, specific heat, vapour resistance and thermal and solar absorbance. It is important to define the correct function temperature-enthalpy for the PCM, which will be adopted into the thermal model. The function must cover the entire range temperature that will be used in the numerical simulation and the function temperature-enthalpy should be provided by the PCM producer.

\section{Choice of phase change materials}

The intervention on the EVOO storage room to improve the energy savings for temperature control was based on the insulation of the partitions and the installation of a false ceiling to limit the air volume, with a two layer panel sandwich, one of PCM and the other of a rigid polyurethane foam with a $4 \mathrm{~cm}$ thick metal cladding. To obtain the PCM layer, about $1 \mathrm{~cm}$ thick boards were used which were composed by two sheets of aluminium that enclosed the phase change material made of salt hydrate and which was produced with different melting temperature, varying from $19^{\circ} \mathrm{C}$ to $29^{\circ} \mathrm{C}$. A simplified energy analysis was conducted, by means of PCM express software, to choose the optimal melting temperature of the phase change material to maintain an air temperature around $22^{\circ} \mathrm{C}$ during the year. The PCM express software is free software based on a finite difference mathematical model and on enthalpy method to simulate the PCM behaviour. PCM

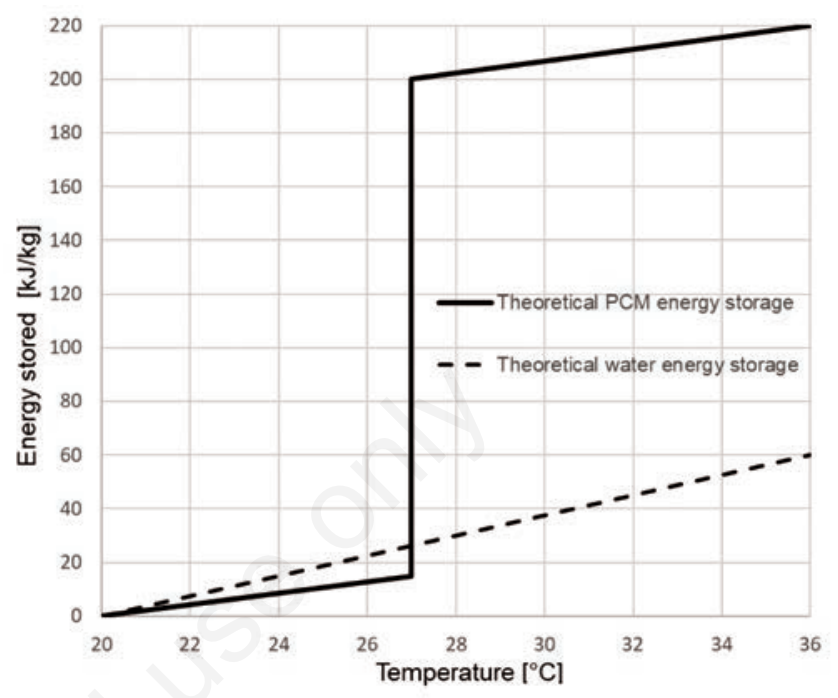

Figure 1. Graph of energy stored and temperature for a phase change materials.

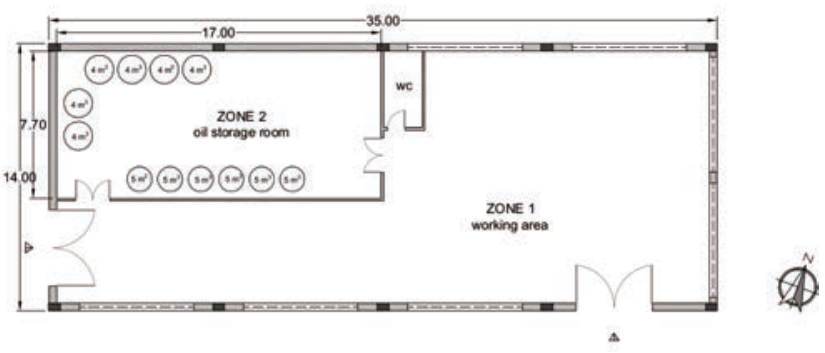

Figure 2. Plan of the olive mill.

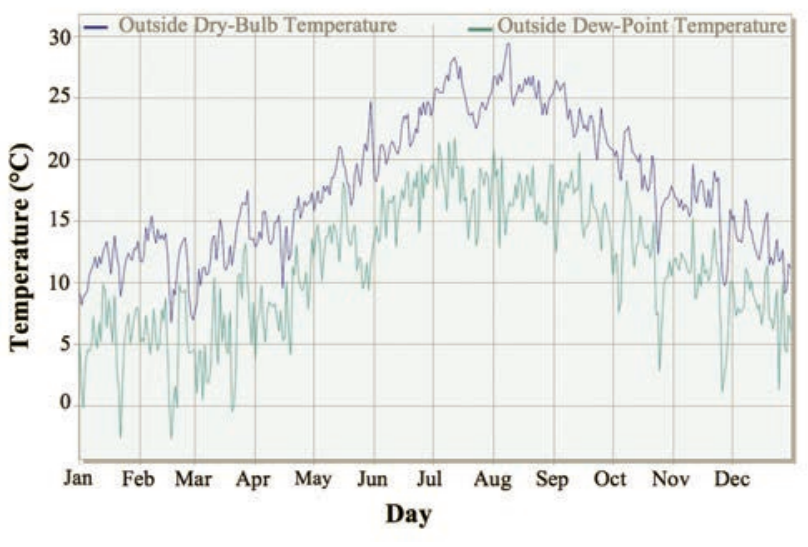

Figure 3. Site average daily temperature of weather station of the World Meteorological Organisation. 
express was created in connection with the research project Development of a user-friendly planning and simulation programme in the combined project 'Active PCM storage systems for Building PCM Active', that ran in collaboration with the Fraunhofer Institute for Solar Energy Systems ISE in Freiburg and partners from industry (Zöller et al., 2008). The best solution, highlighted by means of the energy analysis, was the panel sandwich with a layer of $\mathrm{PCM}$ at $25^{\circ} \mathrm{C}$ melting temperature, this solution allows a yearly energy savings estimated of about 1000 kWh/year (Figure 4).

\section{Thermal analysis}

Thermal analysis requires local weather data in order to model the outdoor weather conditions that are variable during the seasons. The accuracy of the analysis is correlated to the weather data precision. In this paper the thermal analysis was carried out considering the closest WMO weather station $\mathrm{n} .164200$ located about $35 \mathrm{~km}$ West from the olive mill under study $\left(38^{\circ} 12^{\prime} \mathrm{N} ; 15^{\circ} 33^{\prime} \mathrm{E}\right)$, the weather file is part of the Italian Climate Data Set elaborated by Gianni de Giorgio with a yearly data from 1951 until 1970 . The file contains the average hourly statistics for a year of dry and dew bulb temperatures, the relative humidity, the monthly statistics for wind direction and speed and for the global horizontal and normal solar radiation. The weather file was corrected and calibrated by means of a weather data (temperature and humidity) surveyed by a specific station located $50 \mathrm{~m}$ from the modelled building. The calibration procedure was carried out to consider the local microclimate conditions influenced by the orography of the site, in particular different range temperature between day and night. A specific weather file to analyse the building in this manner has been created. The indoor environment of EVOO storage room was conditioned by means of an electric heating, ventilation and air conditioning (HVAC) system. In particular for the EVOO storage a thermal analysis was carried out to evaluate the energy spent to maintain the indoor air temperature around the correct range $\left(8-22^{\circ} \mathrm{C}\right)$. Two different energy models were created: model A, storage room walls without PCM; model $\mathrm{B}$, storage room walls insulated by sandwich panel with PCM (Figure 5 and Table 1). A special attention was paid on modelling accurately the olive oil tanks, in fact the scientific literature shows that a big quantity of liquid stored can remarkably affect the thermal inertia of the building (Benni et al., 2013).

The tanks were modelled as solids whose size corresponds to their real volume, the inertia of steel tanks is negligible because they have thin walls, for this reason in the model were considered only the thermal characteristics of the olive oil (specific heat $=1840 \mathrm{~kJ} / \mathrm{m}^{3}$; thermal conductivity at $20^{\circ} \mathrm{C}=0.17 \mathrm{~W} / \mathrm{mK}$ ) (Turgut et al., 2009). The building's model was divided in two thermal zone, zone 1 the process area of the EVOO, zone 2 the storage room. A thermal analysis simulation, by mean the software DesignBuilder 5.4, was carried out. To calculate a HVAC system's yearly electric energy consumption for controlling air temperature in zone 2 (temperature range of $8-22^{\circ} \mathrm{C}$ ) by a HVAC system (Barreca et al., 2017).

The results were of $3590.67 \mathrm{kWh} /$ year for model A and 2539.52 $\mathrm{kWh} /$ year for model B, with a save of about $30 \%$ of energy.

\section{Results and discussion}

The retrofitting intervention of the buildings was conducted in January 2018 and ended in the same month. The panel sandwich was built in two phases; phase one a $\mathrm{PCM} 25^{\circ} \mathrm{C}$ layer (brand Infinite $\mathrm{R}^{\mathrm{TM}}$ manufactured by INSOLCORP) was applied to the panel sandwich by means of steel structures fixed between the roof and the floor. In phase two a polyurethane layer was installed (Figure 6A). The false ceiling was built by fixing the polyurethane layer to the roof truss and the Infinite R-25 $5^{\mathrm{TM}} \mathrm{PCM} 25^{\circ} \mathrm{C}$ board was spread out on it (Figure 6B).

After the intervention of the storage room (Figure 6C) a thermal survey was conducted to evaluate the thermal performance of the PCM panels. The air temperature of EVOO storage room was monitored from 2 August until 13 September 2018 to intercept the average hottest days in a year. The survey of the temperature was carried out by means of two air temperature sensors, with a resolution of $0.01^{\circ} \mathrm{C}$ and a uncertainty of $0.10^{\circ} \mathrm{C}$ linked to a data logger, one was installed in the storage room and the other was put next to it. The survey allowed to assess the performance of the adopted solution (Barreca and Tirella, 2017). The comparison between the two temperature sensors highlighted, during the hottest year period, a temperature decrease inside the storage room of about $2.5^{\circ} \mathrm{C}$ without a cooling system (Figure 7).

The decrease of the indoor air temperature was observed during

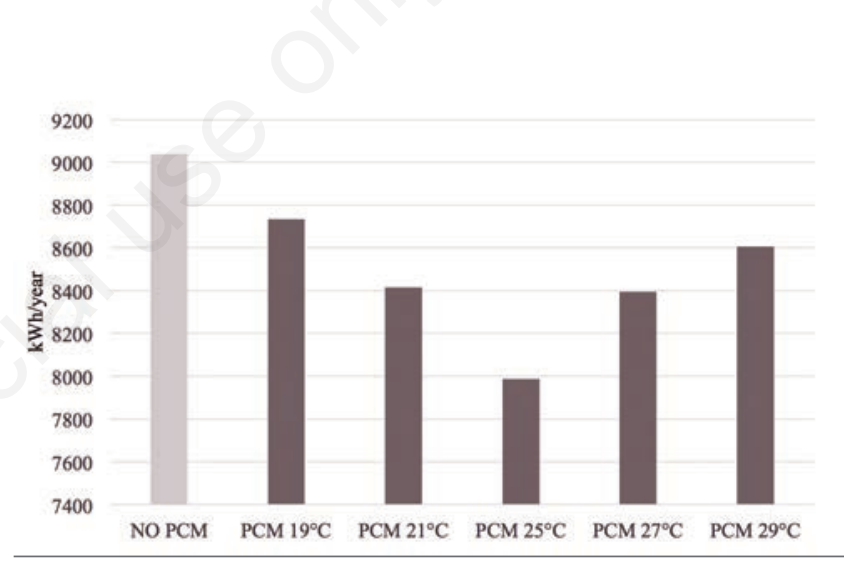

Figure 4. Comparison of phase change materials (PCM) from different yearly energy consumption.
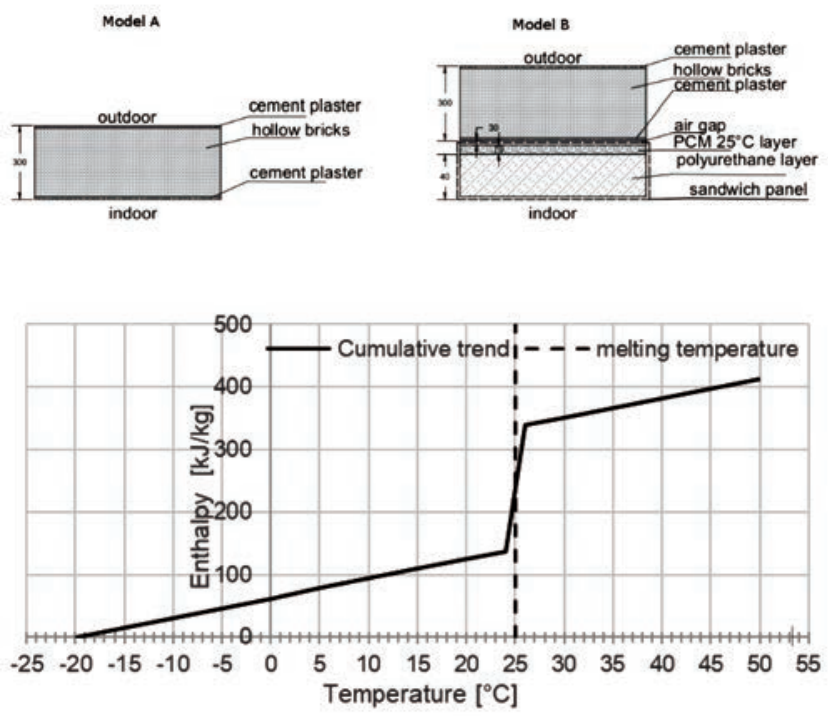

Figure 5. Storage room walls - model $A$ and model $B$ and enthalpy curve of phase change materials (PCM) $25^{\circ} \mathrm{C}$. 
the hottest year season period; this event demonstrated the good performance of the solution adopted. PCM blocks the input flux heat inside the storage room. When the temperature of the PCM board surface increases more than $24-25^{\circ} \mathrm{C}$, the material melts and the changing phase absorbs the exceeded heat flux preventing the indoor air temperature to increase. When the outside air temperature decreases, the phase change material solidifies and the heat outdoor releases the accumulated heat. It is important to note that the best performance of the material is around the melting temperature; in fact if the difference of the PCM work temperature is more than the melting temperature, its behaviour is close to that of a neu- tral thermal behaviour. Instead the second layer of the sandwich panel in polyurethane foam is a thermal resistance for all temperatures and it limits the heat dispersion in a particular way when the external temperature is low (Porto et al., 2017). The most important result was thermal indoor air stabilisation in the storage room. This condition avoids a thermal fluctuation to the EVOO and it is the best storage condition. The quality of EVOO depends strongly on each stage of the production process and also on the environmental condition (Altieri et al., 2015; Pascale et al., 2018). Many studies carried out showed the alteration of the fatty acid composition and the antioxidant activity during the storage stage. Nowadays it is

Table 1. Thermal characteristics of wall layers for model A and model B.

\begin{tabular}{|c|c|c|c|c|c|c|c|c|}
\hline \multirow[t]{2}{*}{ Wall layer } & \multicolumn{4}{|c|}{ Model A } & \multicolumn{4}{|c|}{ Model B } \\
\hline & $\begin{array}{l}\text { Thickness } \\
\text { (m) }\end{array}$ & $\begin{array}{l}\text { Heat capacity } \\
\text { (J/kgK) }\end{array}$ & $\begin{array}{l}\text { Thermal } \\
\text { conductivity } \\
\text { (W/mK) }\end{array}$ & $\begin{array}{l}\text { Density } \\
\left(\mathrm{kg} / \mathrm{m}^{3}\right)\end{array}$ & $\begin{array}{l}\text { Thickness } \\
\text { (m) }\end{array}$ & $\begin{array}{c}\text { Heat capacity } \\
\text { (J/kgK) }\end{array}$ & $\begin{array}{c}\text { Thermal } \\
\text { conductivity } \\
\text { (W/mK) }\end{array}$ & $\begin{array}{l}\text { Density } \\
\left(\mathrm{kg} / \mathrm{m}^{3}\right)\end{array}$ \\
\hline Cement plaster & 0.02 & 840 & 0.720 & 1760 & 0.02 & 840 & 0.720 & 1760 \\
\hline Hollow brick & 0.30 & 840 & 0.300 & 1000 & 0.30 & 840 & 0.300 & 1000 \\
\hline Cement plaster & 0.02 & 840 & 0.720 & 1760 & 0.02 & 840 & 0.720 & 1760 \\
\hline Air gap & & & & & 0.03 & & 0.026 & \\
\hline $\mathrm{PCM} 25^{\circ} \mathrm{C}$ & & & & & 0.007 & 3140 & 0.810 & 570 \\
\hline Polyurethane & & & & & 0.04 & 1470 & 0.028 & 30 \\
\hline
\end{tabular}

PCM, phase change materials.
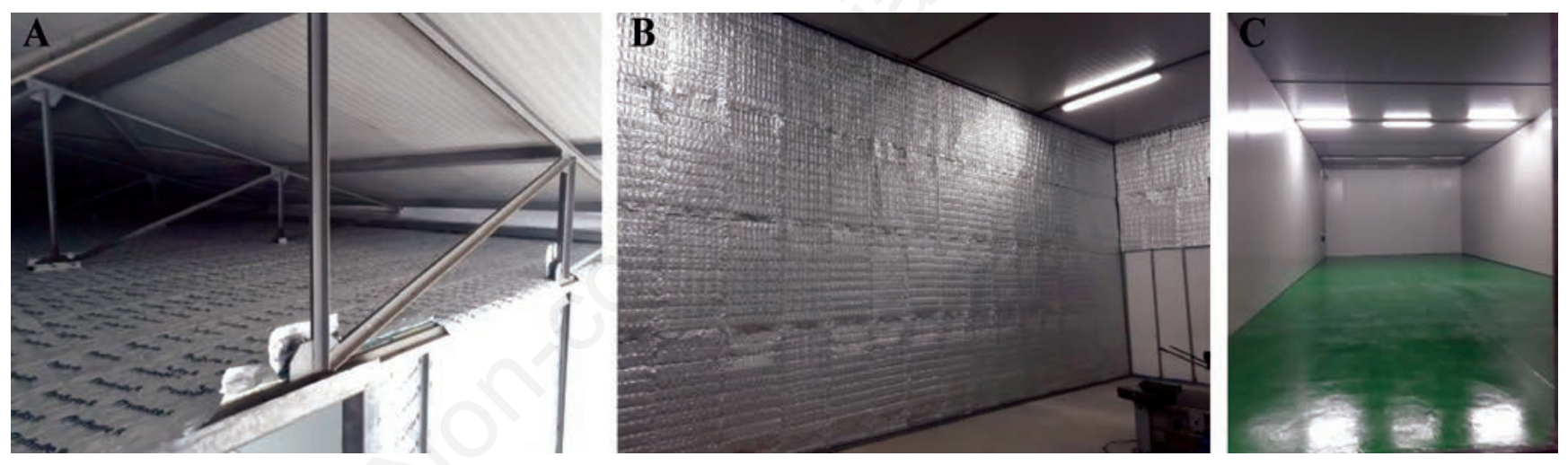

Figure 6. Phase change materials sandwich installation phases.

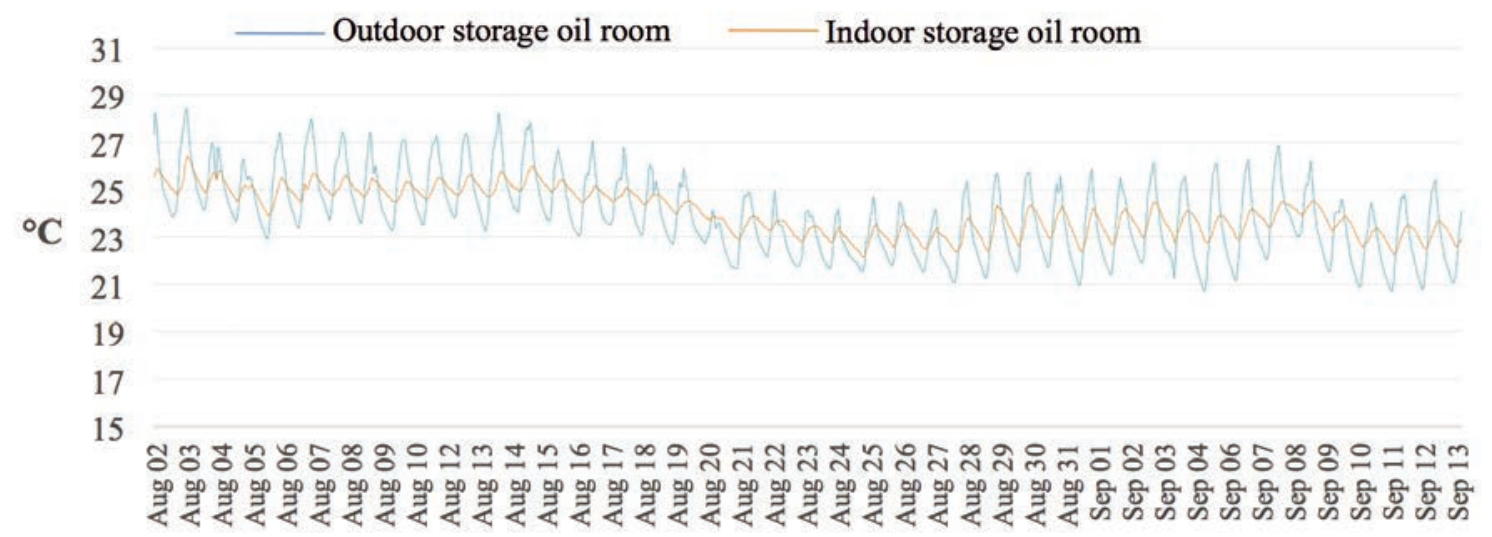

Figure 7. Surveyed measured temperature. 
well known that storage environmental conditions (light, temperature, smell, vibrations) as well as the packing materials (clear PET, can, glass, AISI steel tank) influences the quality of EVOO. In particular there is a strong correlation between temperature and storage time (Escudero et al., 2016) and a more evident effect of a variable storage temperature on the EVOO quality (Li and Wang, 2018). This study is a first stage approach toward the problem solution and the next stage will be the assessment of the qualitative response on oils stored inside the EVOO storage room.

\section{Conclusions}

The case study results demonstrated the efficiency of the PCM to control and to stabilise the indoor temperature with a high-energy savings. Those results are very important for hot climate, because the PCM reduces the input heat flux when the temperature is high and it returns heat to the environment when the temperature decreases. For these reasons the good function of a PCM is related to the variable outdoor temperature. The choice of the best melting temperature value of the PCM is an important phase of a correct design, because the melting phase determines the start of the functioning of the PCM.

The design method in general is not very accurate because it is influenced by different causes: enthalpy temperature curve of the PCM (the factory does not always release an accurate curve), the WMO weather stations are not always nearby; the mathematical model is very complex and the algorithm resolution gives approximate values. The PCM application (Caprara and Stoppiello, 2012) are not widespread in agrifood buildings for these reasons but the PCM in food storage buildings will be very important in the future because the control of temperature in storage stage is fundamental to obtain a high sustainable quality of the production. In fact the quality and the sustainability of food process depend on the building where the process is conducted (Barreca et al., 2014; Barreca and Praticò, 2018). EVOO is appreciated by consumers for its unique sensory characteristics and high nutritional values, for these reasons, the olive oil industry has to monitor oil quality throughout the production line and has to be able to provide realistic information on quality considering the temperature changes during storage and distribution. In fact a correct storage system should forecast not only a temperature control but also a continuous monitoring of the quality of EVOO. This study has not reported the quality parameters of EVOO during the storage stage because the observation time was only for a few months. A future study will be carried out to evaluate the quality parameters of EVOO in a storage room with multilayer walls in PCM.

\section{References}

Altieri G., Genovese F., Tauriello A., Di Renzo G.C. 2015. Innovative plant for the separation of high quality virgin olive oil (VOO) at industrial scale. J. Food Eng. 166:325-34

Ayton J., Mailer R., Kerrie G. 2012. The effect of storage conditions on extra virgin olive oil quality. Available from: https://1 .oliveoiltimes.com/library/Olive-Oil-StorageConditions.pdf

Barbaresi A., De Maria F., Torreggiani D., Benni S., Tassinari P. 2015. Performance assessment of thermal simulation approaches of wine storage buildings based on experimental calibration. Energy Build. 103:307-16.
Barbaresi A., Torreggiani D., Benni S., Tassinari P. 2014. Underground cellar thermal simulation: Definition of a method for modelling performance assessment based on experimental calibration. Energy Build. 76:363-72.

Barreca F., Cardinali G., Fichera C.R., Lamberto L., Modica G., 2014. A fuzzy-based model to implement the global safety buildings index assessment for agri-food buildings. J. Agric. Eng. 45:24.

Barreca F., Fichera C.R. 2013. Wall panels of Arundo donax L. for environmentally sustainable agriculture buildings: thermal performance evaluation. J. Food Agric. Environ. 11:1353-7.

Barreca F., Modica G., Di Fazio S., Tirella V., Tripodi R., Fichera C.R. 2017. Improving building energy modelling by applying advanced 3D surveying techniques on agri-food facilities. J. Agric. Eng. 48:203-8.

Barreca F., Praticò P., 2018. Post-occupancy evaluation of buildings for sustainable agri-food production - a method applied to an olive oil mill. Buildings 8:83.

Barreca F., Tirella V. 2017. A self-built shelter in wood and agglomerated cork panels for temporary use in Mediterranean climate areas. Energy Build. 142:1-7.

Benni S., Torreggiani D., Barbaresi A., Tassinari P. 2013. Thermal performance assessment for energy-efficient design of farm wineries. Trans. ASABE 56:1483-91.

Buonomano A., De Luca G., Montanaro U., Palombo A. 2016. Innovative technologies for NZEBs: An energy and economic analysis tool and a case study of a non-residential building for the Mediterranean climate. Energy Build. 121:318-43.

Caprara C., Stoppiello G. 2012. Heat storage system with phase change materials in cogeneration units: study of preliminary model. J. Agric. Eng. 39:9.

Castell A., Medrano M., Castellón C., Cabeza L.F. 2009. Analysis of the simulation models for the use of PCM in buildings. Effstock Therm. Energy Storage Effic. Sustain. 1-8.

Escudero A., Ramos N., La Rubia M.D., Pacheco R. 2016. Influence of extreme storage conditions on extra virgin olive oil parameters: traceability study. J. Anal. Methods Chem. 2016:7506807.

Gómez-Coca R.B., Fernandes G.D., Pérez-Camino M. del C., Moreda W. 2016. Fatty acid ethyl esters (FAEE) in extra virgin olive oil: A case study of a quality parameter. LWT - Food Sci. Technol. 66:378-83.

ISMEA, 2018. La produzione italiana di olio di oliva. Stime della campagna produttiva 2017/2018. Available from: http://www.ismeamercati.it/flex/cm/pages/ServeBLOB.php/L/ IT/IDPagina/8758

Li X., Wang S.C. 2018. Shelf life of extra virgin olive oil and its prediction models. J. Food Qual. 2018:1-15.

Lo Curto S., Dugo G., Mondello L., Errante G., Russo M.T. 2001. Variation in tocopherol content in Italian virgin olive oils. Ital. J. Food Sci. 13:221-8.

Luca A.I. De, Falcone G., Stillitano T., Iofrida N., Gulisano G. 2018. Evaluation of sustainable innovations in olive growing systems: A Life Cycle Sustainability Assessment case study in southern Italy. J. Clean. Prod. 171:1187-202.

Osterman E., Tyagi V.V., Butala V., Rahim N.A., Stritih U. 2012. Review of PCM based cooling technologies for buildings. Energy Build. 49:37-49.

Pascale R., Bianco G., Cataldi T., Buchicchio A., Losito I., Altieri G., Genovese F., Tauriello A., Renzo G., Lafiosca M., 2018. Investigation of the effects of virgin olive oil cleaning systems on the secoiridoid aglycone content using high performance liquid chromatography-mass spectrometry. J. Am. Oil Chem. 
Soc. 95:665-71.

Piscopo A., Poiana M. 2012. Packaging and storage of olive oil. Olive Germplasm - Olive Cultiv. Table Olive Olive Oil Ind. Italy. IntechOpen, available from: https://www.intechopen. com/books/ olive-germplasm-the-olive-cultivation-table-olive-and-olive-oilindustry-in-italy/packaging-and-storage-of-olive-oil

Porto S.M.C., Valenti F., Bella S., Russo A., Cascone G., Arcidiacono C. 2017. Improving the effectiveness of heat treatment for insect pest control in flour mills by thermal simulations. Biosyst. Eng. 164:189-99.

Stillitano T., De Luca A.I., Iofrida N., Falcone G., Spada E., Gulisano G. 2017. Economic analysis of olive oil production systems in southern Italy. Qual. Access Success. 18:107-12.

Turgut A., Tavman I., Tavman S. 2009. Measurement of thermal conductivity of edible oils using transient hot wire method. Int.
J. Food Prop. 12:741-7.

Valenti F., Arcidiacono C., Chinnici G., Porto S.M.C. 2017. Quantification of olive pomace availability for biogas production by using a GIS-based model. Biofuels Bioprod. Biorefining 11:784-97.

Zolichová L. 2017. Market situation in the olive oil and table olives sectors. Available from: https://ec.europa.eu/info/ sites/info/files/food-farming-fisheries/plants_and_plant_products/documents/market-situation-olive-oil-table-olives_en.pdf

Zöller A., Jung M., Schmidt M., Brenner T., Gatzka B., Schossig P. 2008. Abschlussbericht zum Verbundforschungsvorhaben, Aktive Latentspeichersysteme für Gebäude' Fraunhofer ISE, Gemeinsamer Bericht aller Projektteilnehmer in den Teilprojekten. Available from: http://edok01.tib.uni-hannover.de/edoks/e01fb09/600198391.pdf 